To reference:

Spencer, K. A., Bull, R., Betts, L., \& Winder B. (2019). Executive functioning as a predictive measure of offending behaviour. Journal of Criminal Psychology,

https://doi.org/10.1108/JCP-07-2018-0032

\title{
Executive functioning as a predictive measure of offending behaviour
}

\author{
Karin A. Spenser ${ }^{1}$ \\ Ray Bull ${ }^{1}$ \\ Lucy Betts ${ }^{2}$ \\ Belinda Winder ${ }^{2}$ \\ ${ }^{1 .}$ Department of Criminology and Social Sciences, University of Derby \\ 2. Division of Psychology, Nottingham Trent University
}

Karin A. Spenser and Ray Bull, Department of Criminology and Social Sciences, University of Derby and Lucy R. Betts and Belinda Winder, Division of Psychology, Nottingham Trent University Division of Psychology, Nottingham Trent University, Burton Street, Nottingham, NG1 4BU.

Corresponding author: Karin A Spenser, Department of Criminology and Social sciences, One Friar Gate Square, Derby, DE1 IDZ. Email k.spenser@derby.ac.uk Tel: +44 1332 592608 


\begin{abstract}
Purpose - Prosociality is considered important in the study of offenders and associated cognitive skills: theory of mind, empathic understanding and moral reasoning, are said to enable self-control and reduce the risk of offending behaviours. Previous research has made associations between these skills and executive functioning; however, research into a link between them, in an offending population, is limited. The paper aims to discuss this issue. Design/methodology/approach - To further understand the practicalities of this, the present study considered the predictive abilities of the constructs believed to underpin executive functioning: working memory, cognitive flexibility and inhibitory control, in relation to theory of mind, empathic understanding and moral reasoning. In total, 200 male and female offenders completed measures in all six constructs.
\end{abstract}

Findings - Using path analysis working memory was demonstrated to be predictive of theory of mind and empathic understanding, cognitive flexibility was found to be predictive of theory of mind, and inhibitory control was found to be predictive of theory of mind, empathic understanding and moral reasoning.

Research limitations/implications - The study focussed on offenders serving a custodial sentence of six months or less and did not differentiate between crime categories or take into consideration the socio-environmental backgrounds or ethnicity. Therefore, considering these things could further establish the generalisability of the current findings. It is noted that the more focussed the intervention is to the specific needs of an offender, the greater the impact will be. Therefore, pre-screening tests for the constructs discussed may be able to more accurately assess an offenders' suitability for a programme, or indeed tailor it to meet the specific needs of that person.

Practical implications - These findings may enable practitioners to more accurately assess offenders' suitability for interventions aimed at reducing offending behaviours by improving 
levels of prosociality and develop more focussed programmes to meet the specific needs of individual offenders to reduce re-offending. Social implications - As recommended in the study, a more tailored approach to offender rehabilitation may be a potential aid to reducing levels of recidivism.

Originality/value - The present study adds to the literature as it is the first to consider whether the constructs of executive functioning can predict levels of theory of mind, empathic understanding and moral reasoning and so provide a more accurate method in assessing the cognitive abilities of offenders prior to participation in rehabilitative interventions.

Keywords: Rehabilitation, Offenders, Empathy, Moral reasoning, Theory of mind, Executive functioning 
Prosociality is considered important in the study of offenders. This is because the risk of offending behaviour is believed to be lowered if a person possesses certain prosocial skills (Prior and Paris,2005). From a cognitive perspective, these skills include theory of mind, empathic understanding and moral reasoning (Spenser et al., 2015). Spenser et al. noted that together these skills enable individuals to understand their own, as well as another's, mental and emotional perspectives and behave in a morally acceptable way. Research has linked theory of mind (Russell et al., 2007), empathic understanding (Marques et al., 2015) and moral reasoning (Rueda and Paz-Alonso, 2013) to executive functioning. Executive functioning is a multidimensional cognitive control process (Best and Miller, 2010), described by the Harvard Centre for the Developing Child as "an air-traffic control system for the brain" (Centre on the Developing Child at Harvard University, 2011).

As noted above, an association between executive functioning and theory of mind was first suggested by Russell et al. (2007). This link has intuitive appeal, as, for successful theory of mind, a person must be able to inhibit his or her own perspective, flexibly switch to the mind-set of another and process all the relevant information into a coherent picture. Similarly, there is evidence that executive functioning plays an important role in empathic understanding. For example, Eisenberg and Eggum (2009) indicated that, as well as being the result of affective arousal, empathic understanding may also arise from certain cognitive processes. In particular, Decety (2011) demonstrated that empathic understanding is moderated by how another person is "represented" in an individual conscience. This was evidenced in an earlier study by Hein et al. (2010) who studied the reactions of a group of football enthusiasts whilst they were watching a film of their favoured team fans and those of a rival team experiencing electric shocks. It was reported that more physical and emotional concern was evidenced for the favoured team fans, which may be routed in team rivalry. Executive functioning is likewise believed to play a role in the development of moral 
reasoning. For example, neuroscientific studies have shown that mental abstraction and behavioural regulation share similar neural networks (Decety et al., 2012).

However, to understand the practicalities of the proposed link between executive functioning and theory of mind, empathic understanding and moral reasoning, it is necessary to consider the cognitive abilities underpinning this construct. These abilities have been identified as working memory (Russell et al., 2007), cognitive flexibility (Diamond, 2013) and inhibitory control (Hala et al., 2003). Working memory is a "short-term store" in which individuals temporarily hold small amounts of knowledge or information relating to several mental states or physical situations (Russell et al., 2007). Cognitive flexibility allows a person to move between different mental conditions, whilst taking into account the social and structural rules that may apply to each (Diamond, 2013). This is said to enable people to guide their thoughts in accordance with their intentions or goals (Ponsioen, 2001). Whilst, inhibitory control is the ability to attend to, focus on, and prioritise, whilst deliberately repressing automatic responses based on habits or strong desires (Hala et al., 2003).

However, the literature in support of these proposed links is limited. Gordon and Olson (1998) found a significant positive correlation between performance on a measure for working memory and theory of mind; noting that that a poor working memory was associated with the reduced capacity to simultaneously represent the different pieces of information as required by theory of mind. According to Malti and Latzko (2010), cognitive flexibility is of importance when applying empathic understanding. These researchers noted that empathic concern for the victims of moral wrongdoings may impact upon a child's perception of the seriousness of an act. Lastly, Hughes (1998) found performance in an inhibitory control task related to language and understanding to be positively associated with measured abilities in theory of mind. Further, in the form of self-control, inhibitory control has also been associated with empathic understanding. Echols and Correll (2011), for example, compared 
the neural reactions of doctors and a non-medical control group (matched for both age and IQ) whilst each watching a video of faces, hands and feet being: pricked by a needle, or, being touched by a cotton bud. These researchers noted that the "pain matrix" area of the brain was activated in the control group as they watched the first condition, but not the second. In contrast, the doctors demonstrated no reaction to either condition; thus, suggesting their ability to exercise inhibitory control.

Together, working memory, cognitive flexibility and inhibitory control are said to allow a person to evaluate, organise and achieve goals, as well as flexibly adapt when confronted with novel problems and/or situations (Rueda and Paz-Alonso, 2013). Simply, these skills enable self-control (Rothbart, 2007); a lack of which (often resulting from neglect, abuse and instability) is thought to add to the risk of offending behaviours (Meijers et al., 2015). Simply, any risk factors that a person is exposed to may have a detrimental effect on early childhood brain development that later manifests as limited ability to retain information, loss of control, and a reduced ability to respond is a socially acceptable way (Ganesalingam et al., 2011).

However, whilst past research has demonstrated an association between executive functioning and theory of mind, empathic understanding and moral reasoning, few studies have considered a predictive relationship. Further, research from this perspective has produced inconclusive findings. For example, Hughes (1998) anticipated that early executive functioning would predict performance in ToM but found that this predictive relationship did not hold for all tasks used in his study. In addition, knowledge relating to the relationship between the executive functioning and theory of mind, empathic understanding and moral reasoning appears to be heavily reliant on neuroscientific studies in a non-offending population (Lamm and Majdandžic' , 2015). Finally, there is a paucity of literature specifically in relation to the predictive abilities of executive functioning, as determined by 
working memory, cognitive flexibility and inhibitory control. So, whilst the examination of executive functioning, in terms of theory of mind, empathic understanding and moral reasoning, appears to have shifted from an isolated view to a more associative perspective, additional research is needed in relation to a predictive explanation (Bradford et al., 2015). Therefore, to address these concerns, the present study assessed the ability of working memory, cognitive flexibility and inhibitory control to predict theory of mind, empathic understanding and moral reasoning, in a cohort of male and female offenders. The following hypotheses are proposed:

H1. Working memory will predict: (a) theory of mind, (b) empathic understanding and (c) moral reasoning.

H2. Cognitive flexibility will predict: (a) theory of mind, (b) empathic understanding and (c) moral reasoning.

H3. Inhibitory control will predict: (a) theory of mind, (b) empathic understanding and (c) moral reasoning.

\section{Methodology}

\section{Design}

In psychological research, it is common to study constructs that cannot be directly observed or directly measured; theory of mind (Suminar and Hastjarjo, 2016), empathic understanding (Hojat and LaNoue, 2014), and empathic understanding (Von Weltzien Hoivik, 2004), and executive functioning (Huizinga et al., 2006), are examples. For the purposes of this study executive functioning was reduced to its three main constituent factors: working memory (Gordon and Olson,1998), cognitive flexibility (Welsh et al., 1991) and 
inhibitory control (Hala et al., 2003). A path analysis (IBM SPSS Amos version 23) was adopted as the most appropriate statistical procedure to investigate if abilities in working memory, cognitive flexibility and inhibitory control could predict abilities in theory of mind, empathic understanding and empathic understanding. The model fit was evaluated according to the recommendations of Kline (2011), and included the chi-square likelihood ratio statistic, comparative fit index (CFI), root mean square error of approximation (RMSEA) with associated $90 \% \mathrm{CI}$, and the standardised root mean square residual.

\section{Participants}

In total, 100 male offenders (aged 18- to 55-year olds; M 1/4 27.38, SD 1/4 7.095) were recruited from a male adult, category B, prison in England and 100 female offenders (aged 18- to 55-year olds; M 1/4 30.24, SD 1/4 10.57) were recruited from a female adult, closed category prison in England. Category B male prisons and closed category female prisons house inmates who do not require maximum security, but for whom escape needs to be made difficult. All participants were serving a sentence of six months or less; this representing approximately 47 per cent of the prison population, and of whom approximately 59 per cent are likely to reoffend within one year of release (Prison Reform Trust, 2017). The samples self-selected by responding to posters placed on the wing notice-boards in the prison. As per the recruitment criteria, all participants were English speaking. No upper age limit was specified. No form of compensation was given, and participants were informed that taking part in the study would offer no benefit in relation to their sentence.

\section{Measures}

The following performance-based and self-report questionnaires were used to access theory of mind, moral reasoning, empathic understanding, working memory, cognitive flexibility and inhibitory control. 
Theory of mind. The Social Stories Questionnaire (Lawson et al., 2004) consists of ten vignettes, each divided into three sub-sections containing either: a blatantly offensive utterance, a subtly offence utterance or no offensive utterance. Participants were asked if they thought a sub-section contained an utterance which might upset or offend another character and if so, to identify the dialogue line on which it appeared. Participants were awarded one mark for each target utterance correctly identified, to a maximum of 30 marks. Lawson et al. suggest that a low score indicates a less developed theory of mind, and vice versa. In the current study $\alpha 1 / 40.72$.

Empathic understanding. The empathy quotient (EQ) (Wakabayashi et al., 2006) was selected to measure empathic understanding. Participants read each of the 22 statements and judged the extent to which they agreed using a four-point scale ranging from 1 (strongly agree) to 4 (strongly disagree). Half the items were positively worded (e.g. "I really enjoy caring for other people") and half negatively worded (e.g. "I find it difficult to judge if something is rude or polite"). The order of presentation of the statements was randomised. Participants scored two points if they recorded a strongly empathising response and one point if they recorded a slightly empathising response. Non-empathising responses scored no marks. The highest score obtainable is 44 . The higher the score the more empathic the participant is deemed to be. The EQ is reported to have acceptable internal consistency, with a Cronbach's $\alpha$ coefficient of 0.76 (Wakabayashi et al., 2006). In the current study $\alpha 1 / 40.81$.

Moral reasoning. The Socio-Moral Reflection Measure (Gibbs et al., 1992) assesses moral judgment; including contract, affiliation, life, property, law and legal justice. Participants responded to 11 statements using a three-point scale (very important, important and not important), as well as giving a short reason as to why they had attributed that level of importance to an item. Each reason was assessed by the current first author, matched against standardised answers and scored accordingly $(1.0,1.25,1.5,1.75$ and 2.0 , up to a maximum 
of 4.0). The scores were summed and divided by the number of valid responses (a minimum of seven being required). The measure has been found to discriminate between offenders and non-offenders (Palmer and Begum, 2006) and to be appropriate for both males and females aged from 17 years onwards (r(372) 1/4 0.66; Gibbs et al., 1992). The measure is reported by its developers to have acceptable levels of test and retest reliability, $r(234) 1 / 40.88$, po0.001. In the current study $\alpha 1 / 40.93$.

Executive functioning. Executive functioning is noted as not having a "gold-standard" test used in its measurement (Chan et al., 2008; Salthouse, 2005). One possible explanation for this may lie in its multidimensional nature (Avirett and Mortimer, 2013). For the purposes of the present study, those dimensions were: working memory, cognitive flexibility and inhibitory control (McCloskey et al., 2009), and measures were selected accordingly.

Working memory and cognitive flexibility. The Wechsler Abbreviated Scale of Intelligence (WASI) is recognised to test aspects of executive functioning with the VIQ subscale measuring working memory, and the PIQ subscale measuring cognitive flexibility. Therefore, for the purposes of the present study the WASI (Wechsler, 1999), was used to measure working memory and cognitive flexibility. The test-retest reliabilities of the WASI are reported to range from 0.70 (seven subscales) to 0.90 (two subscales). Inter-scorer coefficients were very high, all being above 0.90 .

Inhibitory control. Von Hippel and Gonsalkorale (2005) suggested the MSCEIT 4th branch entitled "Managing Emotions" (Mayer et al., 2002) was well suited for the measurement of inhibitory control. This test has two subtests that assess how participants control their thoughts and behaviours by rating a number of possible actions ranging from "very ineffective" to "very effective". The scoring criteria were originally determined by public consensus (n 1/4 5,000) or expert scoring (21 members of the International Society 
Research on Emotions). The test-retest reliability for the full-scale MSCEIT V2.0 is $\alpha$ 1/4 0.86. In the current study $\alpha 1 / 40.76$.

\section{Procedure}

Written consent was obtained from all participants in line with both Her Majesty's Prison and Probation Services and the first author's University's ethical approval procedure. Participants were tested individually in an empty room in the prison. The first author sat in the room with the participant to provide help with reading if required. When no help was needed she remained silent, out of the participant's direct line of vision, and at a suitable distance to protect the participant's privacy. At all times a prison officer was stationed outside the room to ensure safety; the officer was not in the participant's direct line of vision and again a suitable distance was maintained to protect the participant's privacy. Each participant was given standard verbal instructions and told that the tests were not timed but should be completed as quickly as possible. The order that the measures were given was varied to reduce order effects.

\section{Results}

To test the hypotheses a path model was generated. All model variables were screened for missing data outliers and tested for assumptions; none were found. The hypothesised pathway is described in Figure 1.

The hypothesised path analysis model was significant; $\chi 2(10, \mathrm{n}=200)=64.998, p<$ .001 , and a non-significant result is required for a good model fit. However, Raykov (2000) stated that when a sample size is 200 participants or over, such results may be disregarded as a large sample is known to routinely produce significant results in path analysis software. Further, in path analysis, several "fit" indices are used to establish whether a model can be accepted. Table I presents the fit indices for the present study. 
The normed fit index (NFI) was 0.935. The NFI (also known as the Bentler-Bonett NFI) can vary from 0 to 1.0 ; with 1.0 equalling the ideal of 100 per cent. The NFI equals the difference between the $\chi^{2}$ of the null model and the $\chi^{2}$ of target model, divided by the $\chi^{2}$ of the null model. In other words, an NFI of 0.935 (as found in the present study) indicates the target model improves the fit by 93.5 per cent relative to the independence model. Byrne (1994) recommended that for an acceptable model fit this figure should exceed 0.90. The CFI was 0.942 . This represents the ratio between the discrepancies of the target model to the discrepancy of the independence model. In simple terms, a value approaching 1.0 suggests that the default model is a better fit than is the independence model (Fan et al., 1999); in the present study this figure is 0.942. Byrne (1994) recommended that for an acceptable model fit this figure should exceed 0.93. Similarly, the incremental fit index in the target model in the present study is 0.944 , which exceeds the recommended figure of 0.90 (Bollen, 1990). The root mean square residual (RMSEA) produced an index of 0.117 , which is greater than the recommended index of 0.08 (Browne and Cudeck, 1993). However, more recently Moss (2016) indicated that whilst zero represents a perfect fit, the maximum should be unlimited, especially when using large participant groups (as in the present study). Marsh et al. (1996) recommend that several fit indices are utilised to overcome individual index limitations and assess the model fit. Therefore, this model was acceptable and post hoc modifications were not conducted.

Six of a possible nine path coefficients were found to be significant at the $p<.001$ level and two were significant at the $p<.05$ level (see Table 2).

To summarise, H1a (that working memory will be predictive of theory of mind) and H1b (that working memory will be predictive of empathic understanding). Similarly, H2a (that cognitive flexibility will be predictive of theory of mind) was supported. Finally, H3a (that inhibitory control will be predictive of theory of mind), H3b (that inhibitory control will 
be predictive of empathic understanding) and $\mathrm{H} 3 \mathrm{c}$ (that inhibitory control will be predictive of Moral reasoning) were supported. All other hypotheses were not supported.

\section{Discussion}

The current study had the aim of investigating whether working memory, cognitive flexibility and inhibitory control would predict theory of mind, empathic understanding and moral reasoning in male and female offenders. The study found that executive functioning, as determined by working memory, cognitive flexibility and inhibitory control, was indeed predictive of theory of mind. One explanation for this may be found in the processing abilities of the construct. For example, Borst et al. (2010) described working memory as a cognitive "bottleneck" in that it is only able to store a limited amount of information for a short period of time before that information is lost. According to Borst et al., this problem is addressed by transforming information into "chunks" that can more easily fit through the "bottleneck"; thus, allowing a person to process complex pieces of information more efficiently. Arslan et al. (2017) noted that a less flexible or deficient working memory may constrain the ability to do this, and so may result in lower scores in complex measures of theory of mind. Spenser et al. (2015) noted that theory of mind is important in the context of offending behaviours. Specifically, these researchers found, in a study of 46 young male offenders and a matched control group, that the offenders had a significantly reduced ability in theory of mind when compared to the non-offenders.

The present study also found cognitive flexibility to be predictive of theory of mind. One explanation for this may lie with the "Cognitive Complexity and Control" theory (Zelazo and Frye, 1998) which states that cognitive flexibility is needed to shift efficiently between multiple incompatible perspectives, descriptions, intentions or situations ( Jacques and Zelazo, 2005). Indeed, Liszkowski (2013) proposed that such flexibility is critical for social understanding. This was supported by Bock et al. (2015) who found cognitive flexibility to be 
positively associated with theory of mind, even after controlling for age and vocabulary. Bock et al. concluded that the ability to make simultaneous judgments, from multiple and sequentially shifting situations, is critical for understanding everyday interactions.

Consequently, deficiencies in cognitive flexibility may be predictive of a reduced theory of mind, which in turn may be a factor related to antisocial or offending behaviours (Spenser et al., 2015).

Inhibitory control was also found to be predictive theory of mind. As noted above, executive functioning is a multifaceted construct that includes the ability to shift between behavioural responses when the "rules" relating to a situation are changed (Lehto et al., 2003). Specifically, inhibitory control refers to the cognitive processes that inhibit automatic responses, and so allow for the accomplishment of goal-directed tasks. Alexander et al. (2002) offered an example, noting that individuals with weaker inhibitory control appear to have difficulty in suppressing their own immediate responses long enough to search in their memory for a more considered response to a given situation. The ability to consider situations from a number of different perspectives to resolve issues and solve problems is a key factor in avoiding offending behaviours (Lösel and Beelmamm, 2005).

As with theory of mind, the present study suggests that executive functioning is generally predictive of empathic understanding. However, in terms of working memory, cognitive flexibility and inhibitory control the present study found working memory and inhibitory control to be predictive of empathic understanding, but not cognitive flexibility, working memory and empathic understanding are core constructs in psychological research; each being considered essential for normal social functioning (Smith et al., 2014). Certainly, each construct has been extensively researched from a developmental (Baron-Cohen and Wheelwright, 2004), social (Blakemore,2008) and neuroscientific (Decety and Jackson, 2004) perspective. However, whilst empathic understanding is said to require an individual to 
extract salient information relating to a given situation and form a coherent "mental" representation, a skill which calls on working memory (Henderson and Hollingworth, 2003), research considering the correlates of the two constructs has to some extent been neglected (Gao et al., 2016). From this perspective, Gao et al. reasoned that the more information a person can store in his or her working memory, the easier it should be for that person to extract social cues from a situation, and so understand the perspective of another. Solomon (2007) noted that the ability of an offender to recognise and manage his or her own emotions, as well as those of others, and subsequently make more effective and controlled life decisions, was crucial for desistance from crime.

In contrast, the ability of cognitive flexibility to predict empathic understanding was not supported by the present study. One important characteristic of cognitive flexibility is the ability to accurately decode and understand numerous "expressions" that may occur during any one social interaction (Gery et al., 2009). Conversely, a reduced ability in cognitive flexibility may be associated with a failure to use salient information to predict the consequences of one's own, as well as another person's, actions (Heinz et al., 2011); and so, lead to social inadequacy or inappropriate behaviours (Tirapu-Ustárroz et al., 2007). Therefore, the findings of the present study were somewhat unexpected. One explanation may be found by noting that Makino (2010) suggested self-report measures (as used in the current study) do not always represent the true feelings and beliefs of an individual. Therefore, future studies may wish to adopt a performance-based measure of cognitive flexibility.

However, the present study did find that inhibitory control was predictive of empathic understanding. According to Eisenberg and Fabes (1998), prosocial individuals tend to be good "inhibiters", with low impulsivity, whereas poor inhibition and high impulsivity are associated with antisocial or offending behaviours. Eisenburg (2007) built on this by 
suggesting that when prosocial behaviours were "costly" to a person, the ability to successfully inhibit automatic responses, from both an emotional and a behavioural perspective, was extremely important. Eisenberg and Eggum (2009) also suggested that individuals who can "inhibit" are less likely to be overwhelmed by their own emotions when witnessing another person in need or distress.

With regards to moral reasoning, neither working memory nor cognitive flexibility was found to be predictive. One explanation for this may be that moral schemas, or frameworks, are thought to reside in long-term memory, and not working memory (Rest et al., 1999). Moral reasoning is said to form when a person notes similarities between his or her remembered experiences. According to Endicott et al. (2003), there are three different frameworks in which these moral schemas fit: the personal interest framework, the maintaining norms framework and the post-conventional framework. The "personal interest framework" is the most primitive and relies on an egocentric and interpersonal perspective. In contrast, the "maintaining norms framework", which usually emerges in adolescence, is characterised by the perceived need for a society-wide system of cooperation and the uniform application of laws and social norms. Finally, the "post-conventional framework", which is the most complex of the three, is characterised by the core belief that "moral obligations [should] be based on shared ideals, which are reciprocal and are open to debate and tests of logical consistency, and on the experience of the community" (Rest et al., 1999, p. 307). Therefore, if moral judgements are based on schemes and frameworks, as well as personal memories, all of which are stored in long-term memory, the findings of the present study appear appropriate in that only working memory was assessed. Therefore, future studies may wish to consider the effect of long-term memory on moral reasoning.

As noted above, the expected predictive relationship between cognitive flexibility and moral reasoning was not found. The hypothesis relating to the predicative abilities of 
cognitive flexibility in relation to moral reasoning was based on Kohlberg's (1969) theory of moral development. Kohlberg suggested that an age-related "shift" in moral reasoning was characterised by a move from a relatively rigid way of thinking to a more flexible style. This flexibility is said to enable a person to utilise the multiple moral schemas that are held in his or her long-term memory (Wilson and Ross, 2003). One explanation for the current study's finding may be found in the theory of "Cognitive Blockade" (Cañas et al., 2006), which is characterised by a tendency to continue with an initial behaviour, even when reasoning suggests that an alternative course of action is required. This was demonstrated by Whitton et al. (2014) who assessed 68 individuals for cognitive flexibility using three types of moral dilemma: benign, impersonal and personal. Whitton et al. concluded that as a result of personal situations or obsessions, some individuals have a more rigid moral reasoning in response to moral dilemmas; thus, offering an explanation for the fact that cognitive flexibility was not shown to be predictive of moral reasoning in present study.

The present study did find that inhibitory control was predictive of moral reasoning. Inhibitory control has been defined as the ability to inhibit dominant, maladaptive responses, either under instruction or in novel or ambiguous situations (Rothbart et al., 2001). Hoffman (2000) noted that IC, as well as regulating emotional responses, plays a role in moral decision making. Indeed, Narvaez (2010) stated that to integrate the rational, emotional and intuitive aspects involved in moral reasoning, the ability to control or inhibit personal responses is needed. Confirmation of this is also found in the earlier work of Eisenberg et al. (1995) who argued that over arousal, resulting from negative affect in moral conflict situations, may lead to personal distress. In contrast, individuals who can inhibit negative effects are thought to experience sympathy and consequently display other-centric response tendencies. In other words, individuals with high levels of inhibitory control can self-regulate, reflect upon their own behaviours and when necessary feel guilt (Malti and Ongley, 2014). Such an association 
has been documented by Gagne and Saudino (2010) who found inhibitory control to be a significant genetic component in terms of similarities in moral behaviours between twins. From this perspective, the self-regulation afforded by inhibitory control (Derryberry and Rothbart, 1997) may play a crucial role in the occurrence of sympathy and reparative behaviours (Malti and Ongley, 2014). Ward and Nee (2009) noted that the ability to make moral decisions from a socially acceptable perspective, the offender must consider his or her behaviours from the point of view of society, as well as his or her own personal values.

There are a number of limitations to the current study. First, it focussed only on offenders serving a custodial sentence of six months or less. As more than 250,000 offenders are currently managed by the probation service (Prison Reform Trust, 2017), future studies may also wish to consider offenders serving a community sentence or under post-sentence supervision. Similarly, as the recidivism rate for individuals serving short sentences in the UK is approximately 59 per cent at the one-year mark (Prison Reform Trust, 2017), future studies may benefit from noting the antecedents (if any) of the participants. Lastly, the present study did not differentiate between the crime categories or take into consideration the socio-environmental backgrounds or ethnicity of either the offending and non-offending groups. Whilst, Chen and Howitt (2007) noted that this is not uncommon, Seruca and Silva (2016) found an association between offending categories and mentally flexibility and Entorf and Spengler (2000) stated that factors such as drug dependency, education or employment status should not be overlooked. Therefore, in the future, a more fine-grained approach could further establish the generalisability of the current findings.

Despite these limitations, the implications of the present study should not be underestimated. A well-known goal of the criminal justice system is to reduce levels of recidivism. Theories as to how this best achieved have shifted recently from a "punish them hard enough and they won't come back" ethos, to a more integrated rehabilitative approach 
(Hooley, 2010, p. 3). In the UK, the Thinking Skills Programme, which aims at addressing offending behaviours by targeting reduced cognitive skills (e.g. theory of mind, empathic understanding, and moral reasoning), is very popular. However, Inciardi et al. (2004) noted that the more focussed the intervention is to the specific needs of an offender, the greater the impact will be. Similarly, Weaver and McNeill (2010) stated that it is essential to allow for individual differences in rehabilitation if desistance is to be achieved. In other words, a onesize-fits-all approach is unlikely to work. Therefore, if executive functioning (broken down into its main constructs of working memory, cognitive flexibility and inhibitory control) is predictive of theory of mind, empathic understanding and moral reasoning, pre-screening tests in these areas may be able to more accurately assess an offenders' suitability for a programme, or indeed tailor it to meet the specific needs of that person.

To conclude, cognitive mechanisms such as the capacity to feel, understand and differentiate between complex thoughts, beliefs and emotions, and to adapt to different social situations are important for successful human social interaction (Marques et al., 2015). To the authors' knowledge, the present study is the first to examine the abilities of the three key subconstructs of executive functioning: working memory, cognitive flexibility and inhibitory control, to predict levels of theory of mind, empathic understanding and moral reasoning; something that may be of interest to practitioners and researchers alike, and as such adds substantially to the literature. 


\section{References}

Alexander, K.W., Goodman, G.S., Schaaf, J.M., Edelstein, R.S., Quas, J.A. and Shaver, P.R. (2002), “The role of attachment and cognitive inhibition in children's memory for a stressful event”, Journal of Experimental Child Psychology, Vol. 83 No. 4, pp. 262-90, doi: 10.1016/S0022-0965(02)00149-2.

Arslan, B., Hohenberger, A. and Verbrugge, R. (2017), "Syntactic recursion facilitates and working memory predicts recursive theory of mind", PLoS One, Vol. 12 No. 1, doi: org/10.1371/journal.pone.0169510.

Avirett, E.K. and Mortimer, J.E. (2013), "Executive functions: from assessment to intervention (PowerPoint slides)", available at: http://citeseerx.ist.psu.edu/viewdoc/download?doi=10.1.1.624.7191\&rep=rep1\&type=p $\underline{\mathrm{df}}$

Baron-Cohen, S. and Wheelwright, S. (2004), “The empathy quotient: an investigation of adults with asperger syndrome or high functioning autism, and normal sex differences ”, Journal of Autism and Developmental Disorders, Vol. 34, pp. 163-75, doi: 10.1023/2FB-3AJADD.0000022607.19833.00.

Best, J.R. and Miller, P.H. (2010), “A developmental perspective on executive function”, Child Development, Vol. 81 No. 6, pp. 1641-60, doi: 10.1111/j.14678624.2010.01499.x.

Blakemore, S.J. (2008), "The social brain in adolescence”, Nature Reviews Neuroscience, Vol. 9 No. 4, pp. 267-77, doi: 10.1038/nrn2353.

Bock, A.M., Gallaway, K.C. and Hund, A.M. (2015), "Specifying links between executive functioning and theory of mind during middle childhood: cognitive flexibility predicts social understanding”, Journal of Cognition and Development, Vol. 16 No. 3, pp. 50921, doi: 10.1080/15248372.2014.888350. 
Bollen, K.A. (1990), "Political democracy: conceptual and measurement traps", Studies in Comparative International Development, Vol. 25 No. 1, pp. 7-24.

Borst, J.P., Taatgen, N.A. and Van Rijn, H. (2010), “The problem state: a cognitive bottleneck in multitasking", Journal of Experimental Psychology: Learning, Memory, and Cognition, Vol. 36 No. 2, pp. 363-82, doi: 10.1037/a0018106.

Bradford, E.E., Jentzsch, I. and Gomez, J.-C. (2015), "From self to social cognition: theory of mind mechanisms and their relation to executive functioning", Cognition, Vol. 138, pp. 21-34, doi: 10.1016/j.cognition.2015.02.001.

Browne, M.W. and Cudeck, R. (1993), “Alternative ways of assessing model fit”, in Bollen, K.A. and Long, J.S. (Eds), Testing Structural Equation Models, Sage, Newbury Park, CA, pp. 136-62.

Byrne, B.M. (1994), Structural Equation Modelling with EQS and EQS/Windows, ISBN-10: 0803950926, Sage Publications, Thousand Oaks, CA.

Cañas, J.J., Fajardo, I. and Salmerón, L. (2006), “Cognitive flexibility”, International Encyclopaedia of Ergonomics and Human Factors, pp. 297-300, doi: $10.13140 / 2.1 .4439 .6326$.

Chan, R.C.K., Shum, D., Toulopoulou, T. and Chen, E.Y.H. (2008), “Assessment of executive functions: review of instruments and identification of critical issues", Archives of Clinical Neuropsychology, Vol. 23 No. 2, pp. 201-16.

Chen, C. and Howitt, D. (2007), "Different crime types and moral reasoning development in young offenders compared with non-offender controls", Psychology, Crime \& Law, Vol. 13 No. 4, pp. 405-16, doi: 10.1080/10683160601060788.

Decety, J. (2011), “Dissecting the neural mechanisms mediating empathy”, Emotional Review, Vol. 3, pp. 92-108, doi: 10.1177/1754073910374662. 
Decety, J. and Jackson, P.L. (2004), “The functional architecture of human empathy”, Behavioural and Cognitive Neuroscience Reviews, Vol. 3, pp. 71-100, doi: org/10.1177/1534582304267187.

Decety, J., Michalska, K.J. and Kinzler, K.D. (2012), “The contribution of emotion and cognition to moral sensitivity: a neurodevelopmental study", Cerebral Cortex, Vol. 22, pp. 209-20, doi: 10.1093/cercor/bhr111.

Derryberry, D. and Rothbart, M.K. (1997), "Reactive and effortful processes in the organization of temperament", Development and Psychopathology, Vol. 9, pp. 633-52.

Diamond, A. (2013), “Executive functions”, Annual Review Psychology, Vol. 64, pp. 135-68. Echols, S. and Correll, J. (2011), 'It's more than skin deep: empathy and helping behaviour across social groups", in Decety, J. (Ed.), Empathy: From Bench to Bedside, MIT Press, Cambridge, MA, pp. 55-72.

Eisenburg, N. (2007), Handbook of Child Psychology, Wiley, Hoboken, NJ, doi: 10.1002/9780470147658. chpsy0311.

Eisenberg, N. and Eggum, N.D. (2009), "Empathic responding: sympathy and personal distress", in Decety, J. and Ickes, W. (Eds), The Social Neuroscience of Empathy, MIT Press, Cambridge, MA, pp. 71-83, doi: 10.1177/1754073911402373.

Eisenberg, N. and Fabes, R. (1998), "Pro-social development”, in Damon, W. and Eisenberg, N. (Eds), Handbook of Child Psychology: Social, Emotional, and Personality Development, Vol. 3, 5th ed., Wiley, New York, NY, pp. 701-78.

Eisenberg, N., Carlo, G., Murphy, B.C. and van Court, P. (1995), "Prosocial development in late adolescence:a longitudinal study", Child Development, Vol. 66 No. 4, pp. 1179-97. Endicott, L., Bock, T. and Narvaez, D. (2003), "Moral reasoning, intercultural development, and multicultural experiences: relations and cognitive underpinnings", International Journal of Intercultural Relations, Vol. 27 No. 4, pp. 403-19. 
Entorf, H. and Spengler, H. (2000), "Socio-economic and demographic factors of crime in Germany: evidence from panel data of the German States", International Review of Law and Economics, Vol. 20 No. 1, pp. 75-106.

Fan, X., Thompson, B. and Wang, L. (1999), “The effects of sample size, estimation methods, and model specification on SEM fit indices", Structural Equation Modelling, Vol. 6 No. 1, pp. 56-83, doi: org/10.1080/10705519909540119.

Gagne, J.R. and Saudino, K.J. (2010), "Wait for it! A twin study of inhibitory control in early childhood",Behavior Genetics, Vol. 40 No. 3, pp. 327-37.

Ganesalingam, J., An, J., Shaw, C.E., Shaw, G., Lacomis, D. and Bowser, R. (2011), "Combination of neurofilament heavy chain and complement C3 as CSF biomarkers for ALS", Journal of Neurochemistry, Vol. 17 No. 3, pp. 528-37.

Gao, Z., Ye, T., Shen, M. and Perry, A. (2016), “Working memory capacity of biological movements predict's empathy traits”, Psychonomic Bulletin \& Review, Vol. 23 No. 2, pp. 468-75.

Gery, I., Miljkovitch, R., Berthoz, S. and Soussignan, R. (2009), "Empathy and recognition of facial expressions of emotion in sex offenders, non-sex offenders and normal controls ”, Psychiatry Research, Vol. 165, pp. 252-62, doi: 10.1016/j.psychres.2007.11.006.

Gibbs, J.C., Basinger, K.S., Fuller, D. and Fulkler, R.L. (1992), Moral Maturity: Measuring the Development of Sociomoral Reflection, Lawrence Erlbaum Associates. Inc., Hillsdale, NJ.

Gordon, A.C.L. and Olson, D.R. (1998), “The relation between acquisitions of a theory of mind and the capacity to hold in mind", Journal of Experimental Child Psychology, Vol. 68 No. 1, pp. 70-83, doi: 10.1006/ jecp.1997.2423. 
Hala, S., Hug, S. and Henderson, A. (2003), "Executive function and false-belief understanding in preschool children: two tasks are harder than one", Journal of Cognition and Development, Vol. 4 No. 3, pp. 275-98, doi: 10.1207/S15327647JCD0403_03.

Hein, G., Silani, G., Preuschoff, K., Batson, C.D. and Singer, T. (2010), “Neural responses to ingroup and outgroup members' suffering predict individual differences in costly helping", Neuron, Vol. 68 No. 1, pp. 149-60, doi: 10.1016/j.neuron.2010.09.003.

Heinz, A.J., Beck, A., Meyer-Lindenberg, A., Sterzer, P. and Heinz, A. (2011), “Cognitive and neurobiological mechanisms of alcohol-related aggression”, Nature Reviews Neuroscience, Vol. 12 No. 7, pp. 400-13, doi: 10.1038/nrn3042.

Henderson, J.M. and Hollingworth, A. (2003), "Eye movements and visual memory: detecting changes to saccade targets in scenes", Perception \& Psychophysics, Vol. 65, pp. $58-71$.

Hoffman, M.L. (2000), Empathy and Moral Development: Implications for Caring and Justice, Cambridge University Press, New York, NY.

Hojat, M. and LaNoue, M. (2014), "Exploration and confirmation of the latent variable structure of the Jefferson scale of empathy", International Journal of Medical Education, Vol. 5, pp. 73-81, doi: 10.5116/ijme.533f.0c4.

Hooley, J.M. (2010), "Social factors in Schizophrenia”, Current Directions in Psychological Science, Vol. 19 No. 4, pp. 238-42, doi: 10.1177/0963721410377597.

Hughes, C. (1998), "Executive function in pre-schoolers: links with theory of mind and verbal ability", British Journal of Developmental Psychology, Vol. 16 No. 2, pp. 233 53, doi: 10.1111/j.2044-835X.1998.tb00921.x.

Huizinga, M., Dolan, C.V. and van der Molen, M.W. (2006), “Age-related change in executive function: developmental trends and a latent variable analysis", 
Neuropsychologia, Vol. 44 No. 11, pp. 2017-36, doi:

10.1016/j.neuropsychologia.2006.01.010.

Inciardi, J.A., Martin, S.S. and Clifford, A.B. (2004), "Five year outcome of therapeutic community treatment of drug-involved offenders after release from prison", Crime and Delinquency, Vol. 50 No. 1, pp. 88-107.

Jacques, S. and Zelazo, P.D. (2005), "Language and the development of cognitive flexibility: implications for theory of mind", in Astington, J.W. and Baird, J.A. (Eds), Why Language Matters for Theory of Mind, Oxford University Press, New York, NY, pp. 144-62, doi: 10.1093/acprof:oso/9780195159912.003.0008.

Kline, R.B. (2011), Principles and Practice of Structural Equation Modeling, Guilford, New York, NY.

Kohlberg, L. (1969), "Stage and sequence: the cognitive-developmental approach to socialization", in Goslin, D. (Ed.), Handbook of Socialization Theory and Research, Rand McNally, Chicago, IL, pp. 347-480, doi: 10.12691/education-3-9-16.

Lamm, C. and Majdandžic' , J. (2015), “The role of shared neural activations, mirror neurons, and morality in empathy: a critical comment”, Neuroscience Research, Vol. 90, pp. 15-24, doi: 10.1016/j. neures.2014.10.008.

Lawson, J., Baron-Cohen, S. and Wheelwright, S. (2004), "Empathising and systemising in adults with and without Asperger's syndrome”, Journal of Autism and Developmental Disorders, Vol. 34 No. 3, pp. 301-10.

Lehto, J.E., Juujärvi, P., Kooistra, L. and Pulkkinen, L. (2003), “Dimensions of executive functioning: evidence from children", British Journal of Developmental Psychology, Vol. 21 No. 1, pp. 59-80, doi: 10.1348/026151003321164627.

Liszkowski, U. (2013), "Using theory of mind”, Child Development Perspectives, Vol. 7 No. 2, pp. 104-9, doi: 10.1111/cdep.12025. 
Lösel, F. and Beelmamm, A. (2005), "Social problem-solving programs for preventing antisocial behaviour in children and youth”, in McMorran, M. and McGuire, J. (Eds), Social Problem Solving and Offending: Evidence, Evaluation and Evolution, Wiley, New York, NY, pp. 127-43.

McCloskey, G., Perkins, L. and Van Divner, B. (2009), Assessment and Intervention for Executive Function Difficulties, Routledge/Taylor \& Francis Group, New York, NY.

Makino, H. (2010), “The development of a new performance-based test for measuring emotional intelligence: humanity-empathy-assertiveness-respect test”, unpublished doctoral thesis, UMI No. 3409390, UMI Dissertation Publishing, Liberty University, Lynchburg, VA.

Malti, T. and Latzko, B. (2010), “Children's moral emotions and moral cognition: towards an integrative perspective”, New Directions in Child and Adolescent Development, Vol. 129, pp. 1-10, doi: 10.1002/cd.276.

Malti, T. and Ongley, S. (2014), “The development of moral emotions and moral reasoning”, in Killen, M. and Smetana, J. (Eds), Handbook of Moral Development, 2nd ed., Psychology Press, New York, NY, pp. 163-83.

Marques, T., Pereira, A.I., Goes, A.R. and Barros, L. (2015), Interpretation Bias, Judgment Bias and Coping Strategies in Anxious Children, International Convention of Psychological Science, University of Amsterdam, Amsterdam, doi: 10.1590/16787153.201528304.

Marsh, H.W., Balla, J.R. and Hau, K.T. (1996), “An evaluation of incremental fit indices: a clarification of mathematical and empirical properties", in Marcoulides, G.A. and Schumacher, R.E. (Eds), Advanced Structural Equation Modelling Issues and Techniques, Erlbaum, Mahwah, NJ, pp. 315-53. 
Mayer, J.D., Salovey, P. and Caruso, D.R. (2002), Mayer-Salovey-Caruso Emotional Intelligence Test (MSCEIT) User's Manual, Multi-Health Systems, Toronto.

Meijers, J., Harte, J.M., Jonker, F.A. and Meynen, G. (2015), “Prison brain? Executive dysfunction in prisoners", Frontiers in Psychology, Vol. 2015 No. 6, pp. 1-6.

Moss, S. (2016), "Fit indices for structural equation modelling”, available at: www.sicotests.com/psyarticle. asp?id=277 (accessed 9 August 2017).

Narvaez, D. (2010), “The embodied dynamism of moral becoming”, Perspectives on Psychological Science, Vol. 5 No. 2, pp. 185-6, doi: 10.1177/1745691610362353.

Palmer, E.J. and Begum, A. (2006), “The relationship between moral reasoning, provictim attitude and interpersonal aggression among imprisoned young offenders”, International Journal of Offending Theory and Comparative Criminology, Vol. 50 No. 4, pp. 446-457.

Ponsioen, A.J.G.B. (2001), “Cognitive skills of mildly mentally disabled children and young people", unpublished academic thesis, Amsterdam.

Prior, D. and Paris, A. (2005), “Preventing children's involvement in crime and antisocial behaviour: a literature review", a paper produced for the National Evaluation of the Children's Fund Institute of Applied Social Studies, Institute of Applied Social Sciences, Department of Education and Skills, ISBN 184478421 5, University of Birmingham, available at: https://dera.ioe.ac.uk/5557/1/RR623.pdf

Prison Reform Trust (2017), “Prison: the facts. Bromley briefings summer 2017”, Prison Reform Trust Home, available at: www.prisonreformtrust.org.uk/Portals/0/Documents/Bromley\%20Briefings/Autumn\%2 02017\%20factfile.pdf

Raykov, T. (2000), “On the large-sample bias, variance, and mean squared error of the conventional noncentrality parameter estimator of covariance structure models", 
Structural Equation Modelling, Vol. 7 No. 3, pp. 431-41, doi:

10.1207/S15328007SEM0703_4.

Rest, J., Narvaez, D., Bebeau, M. and Thoma, S. (1999), “A Neo-Kohlbergian approach: the DIT and schema theory", Educational Psychology Review, Vol. 11 No. 4, pp. 291-324. Rothbart, M.K. (2007), “Temperament, development, and personality”, Current Directions in Psychological Science, Vol. 16 No. 4, pp. 207-12, doi: org/10.1111/j.14678721.2007.00505.x.

Rothbart, M.K., Ahadi, S.A., Hershey, K. and Fisher, P. (2001), "Investigations of temperament at three to seven years: the children's behavior questionnaire", Child Development, Vol. 72 No. 5, pp. 1394-408, doi: 10.1111/1467-8624.00355.

Rueda, M.R. and Paz-Alonso, P.M. (2013), "Executive function and emotional development”, in Tremblay, R.E., Boivin, M. and Peters, R.D. (Eds), Encyclopaedia on Early Childhood Development, Centre of Excellence for Early Childhood Development and the Strategic Knowledge Cluster on ECD, Montreal, QC, pp. 1-6.

Russell, T.A., Tchanturia, K., Rahman, Q. and Schmidt, U. (2007), "Sex differences in theory of mind: a male advantage on Happe's 'cartoon' task”, Cognition and Emotion, Vol. 21 No. 7, pp. 1554-64, doi: 10.1080/02699930601117096.

Salthouse, T.A. (2005), "Relations between cognitive abilities and measures of executive functioning”, Neuropsychology, Vol. 19, pp. 532-45, available at:

\section{http://dx.doi.org/10.1037/0894-4105.19.4.532}

Seruca, T. and Silva, C.F. (2016), "Executive functioning in criminal behaviour: differentiating between types of crime and exploring the relation between shifting, inhibition, and anger”, International Journal of Forensic Mental Health, Vol. 15 No. 3, pp. 235-46, doi: 10.1080/14999013.2016.1158755. 
Smith, J.L., Mattick, R.P., Jamadar, S.D. and Iredale, J.M. (2014), "Deficits in behavioural inhibition in substance abuse and addiction: a meta-analysis", Drug and Alcohol Dependency, Vol. 145, pp. 1-33.

Solomon, J.A. (2007), “Contrast discrimination: second responses reveal the relationship between the mean and variance of visual signals", Vision Research, Vol. 47, pp. 324758.

Spenser, K.A., Betts, L.R. and Das Gupta, M. (2015), "Deficits in prosocial skills: a comparison between young-adult offenders and non-offenders", Psychology, Crime and Law, Vol. 21 No. 7, pp. 632-47.

Suminar, D.R. and Hastjarjo, T.D. (2016), “A theoretical model of theory of mind and pretend play”, International Journal of Applied Psychology, Vol. 6 No. 4, pp. 85-93.

Tirapu-Ustárroz, J., Pérez-Sayes, G., Erekatxo-Bilbao, M. and Pelegrín-Valero, C. (2007), "What is the theory of the mind?", Journal of Neurology, Vol. 44, pp. 479-89.

Von Hippel, W. and Gonsalkorale, K. (2005), “' 'That is bloody revolting!' Inhibitory control of thoughts better left unsaid”, Psychological Science, Vol. 16 No. 7, pp. 497-500, doi: 10.1111/j.0956-7976.2005.01563.x.

Von Weltzien Hoivik, H. (2004), “The concept of moral imagination: an inspiration for writing and using case histories in business ethics?", Journal of Business Ethics Education, Vol. 1 No. 1, pp. 29-42.

Wakabayashi, A., Baron-Cohen, S., Wheelwright, S., Goldenfeld, N., Delany, J., Fine, D., Smith, R. and Weil, L. (2006), "Development of short forms of the empathy quotient (EQ-short) and the systemising quotient (SQ-short)", Personality and Individual Differences, Vol. 41 No. 2, pp. 929-40, doi: 10.1016/j.paid.2006.03.017.

Ward, T. and Nee, C. (2009), "Surfaces and depths: evaluating the theoretical assumptions of the cognitive skills programmes", Psychology, Crime \& Law, Vol. 15, pp. 165-82. 
Weaver, B. and McNeill, F. (2010), “Travelling hopefully: desistance research and probation practice", in Brayford, J., Cowe, F. and Deering, J. (Eds), What Else Works? Creative Work with Offenders, Willan, Cullompton.

Wechsler, D. (1999), Wechsler Abbreviated Scale of Intelligence, The Psychological Corporation: Harcourt Brace \& Company, New York, NY.

Welsh, K., Butters, N., Hughes, J., Mohs, R. and Heyman, A. (1991), "Detection of abnormal memory decline in mild cases of Alzheimer's disease using CERAD neuropsychological measures", Archives of Neurology, Vol. 48 No. 3, pp. 278-81.

Whitton, A.E., Henry, J.D., Rendell, P.G. and Grisham, J.R. (2014), “Disgust, but not anger provocation, enhances levator labii superioris activity during exposure to moral transgressions”, Biological Psychology, Vol. 96 No. 1, pp. 48-56, doi: $10.1177 / 1948550617722831$.

Wilson, A. and Ross, M. (2003), "The identity function of autobiographical memory: time is on our side", Memory, Vol. 11 No. 2, pp. 137-49, doi: 10.1080/741938210.

Zelazo, P.D. and Frye, D. (1998), “Cognitive complexity and control: II: the development of executive function in childhood", Current Directions in Psychological Science, Vol. 7 No. 3, pp. 121-6. 
Table 1 Results for path analysis for executive functioning to predict theory of mind, empathic understanding and moral reasoning

\begin{tabular}{ccccccc}
\hline NFI & CFI & IFI & RMSEA & $\chi 2$ & df & Probability \\
\hline .935 & .942 & .944 & .117 & 64.995 & 10 & $<.001$
\end{tabular}

Note: Because AMOS is unable to incorporate means and intercepts, the current model used estimates. For this reason a goodness of fit index (GFI) was not calculated 
Table 2 Standardised path coefficients

$\begin{array}{lll}\text { Theory of mind } & \text { Empathic } & \text { Moral reasoning } \\ & \text { understanding }\end{array}$

\begin{tabular}{llll}
\hline Working memory & $.24^{* * *}$ & $.24^{* * *}$ & .00 \\
Cognitive flexibility & $.20^{* * *}$ & .05 & .01 \\
Inhibitory control & $.12^{*}$ & $.25^{* * *}$ & $.97^{* * *}$
\end{tabular}

Note: $*$,***Indicate values of $p<.05 ; p<.001$, respectively 


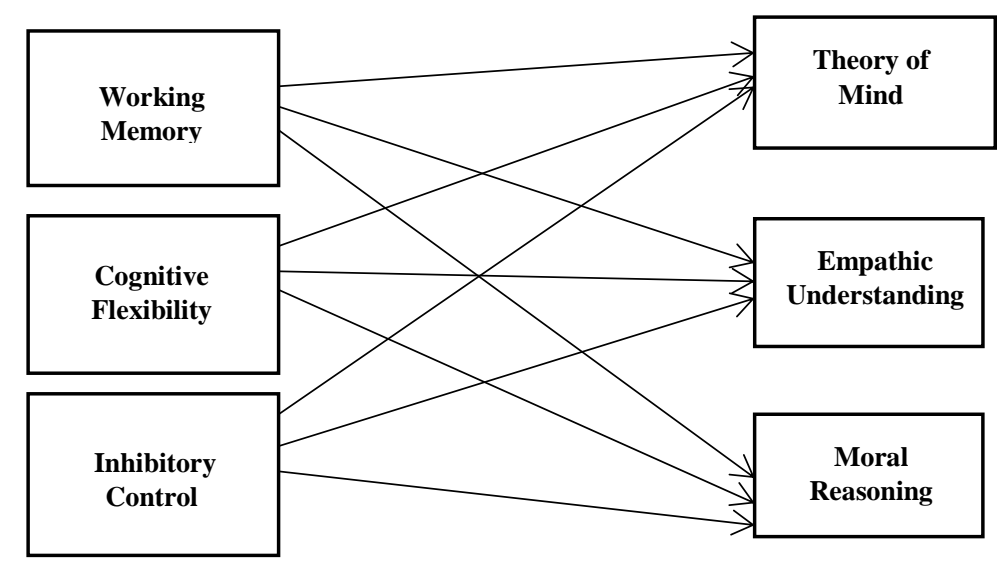

Figure 1: Hypothesised Path Analysis for WM, CF, and IC to predict ToM, EU, and MR 